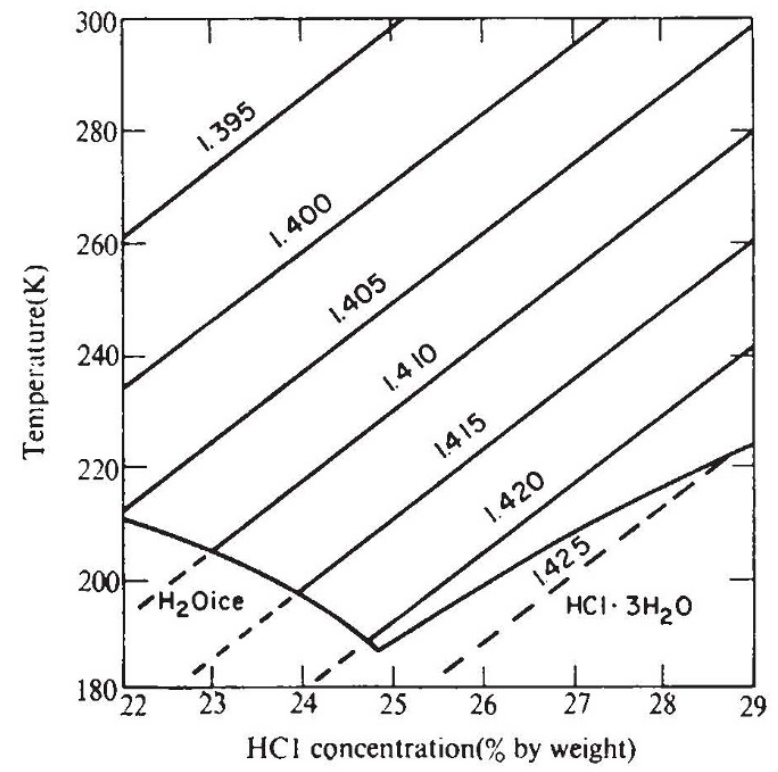

Fig. 2 Refractive index, $n_{F}$, at low temperatures. Density data of Garrett et al. ${ }^{11}$ were used in conjunction with the Lorentz-Lorenz equation to calculate $n_{\mathrm{F}}$ at temperatures for which no direct measurements exist. The freezing lines for precipitation of $\mathrm{H}_{2} \mathrm{O}$ ice and solid $\mathrm{HCl} .3 \mathrm{H}_{2} \mathrm{O}$ are indicated. Refractive index isopleths drawn in below the equilibrium freezing lines refer to supercooled solution, not to the solids.

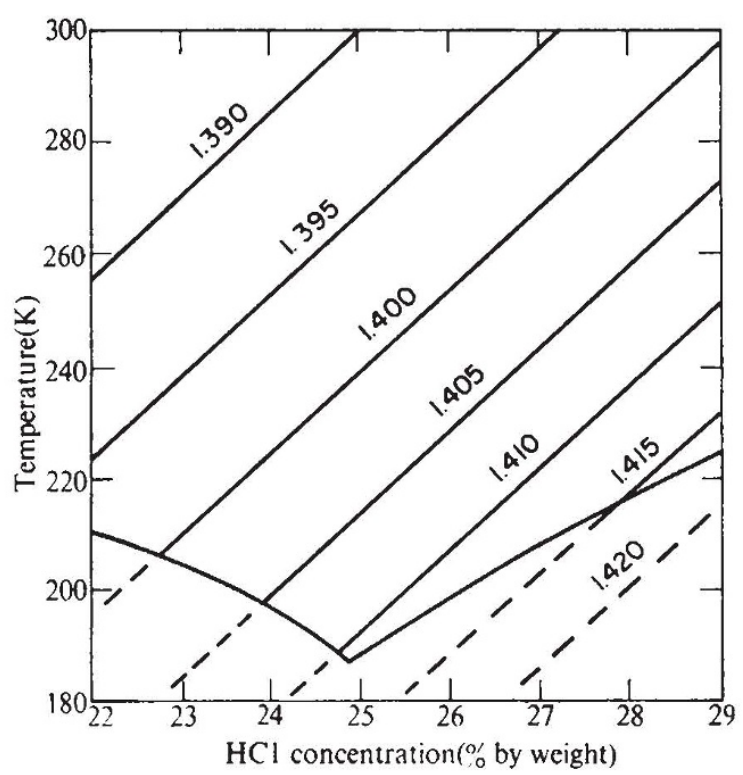

Fig. 3 Refractive index $n_{D}$ at low temperatures (see legend to Fig. 2).

Values of $n_{\mathrm{F}}$ and $n_{\mathrm{D}}$ calculated by means of the LorentzLorenz equation for $\mathrm{HCl}$ solutions between 22 and $29 \%$ by weight $\mathrm{HCl}$ and from 180 to $300 \mathrm{~K}$ are shown in Figs. 2 and 3 , respectively. The equilibrium freezing lines are drawn in for reference.

A refractive index of $n_{\mathrm{F}} \geq 1.42$ corresponds to the cloud formation conditions given by Lewis? ${ }^{7}$. Indeed, the most crucial questions affecting the plausibility of such clouds on Venus concern the true thermal structure of the atmosphere of Venus near the 50 mbar level. Lewis ${ }^{6,7}$ has stressed the extremes necessary to condense water, in any form, in the Venus clouds. I think that rejection of $\mathrm{HCl}$ solution clouds because of the discrepancy between the $\sim 1.420$ to 1.428 values which I have calculated, and the $1.45 \pm 0.02$ found by Hansen, is extremely unwise. Although I would not assign a high $a$ priori probability to the existence of such an $\mathrm{HCl}$ solution haze layer on Venus, I consider this more probable than the alternative, $\mathrm{C}_{3} \mathrm{O}_{2}$. Carbon suboxide has a vapour pressure so high that it exceeds, by at least a factor of $10^{3}$, the spectroscopic upper limit on gaseous $\mathrm{C}_{3} \mathrm{O}_{2}$. Furthermore, there is a high probability that the refractive index of $\mathrm{C}_{3} \mathrm{O}_{2}$ at $<240 \mathrm{~K}$ is $>1.49$.

Although conclusive identification of the chemical constituents of Venus's clouds is not yet possible, the accumulating evidence eliminates most of the proposed alternatives. Perhaps the most interesting conclusion will concern the presence or absence of pure liquid water and $\mathrm{H}_{2} \mathrm{O}$ ice clouds, but current evidence is against the possibility of their existence on Venus ${ }^{1-3,6,7,12}$.

This work was supported in part by NASA.

JOHN S. LEWIS

Planetary Astronomy Laboratory,

Department of Earth and Planetary Sciences, and Department of Chemistry, Massachusetts Institute of Technology

Received February 3, 1971.

1 Arking, A., and Potter, J., J. Atmos. Sci., 25, 617 (1968).

2 Coffeen, D. L., Astron. J., 74, 446 (1969).

3 Coffeen, D. L., and Gehrels, T., Astron. J., 74, 433 (1969).

${ }^{4}$ McElroy, M. B., J. Geophys. Res., 73, 1513 (1968).

${ }^{3}$ Harteck, P., Reeves, R. R., and Thompson, B. A., NASA TN D-1984 (1963).

${ }^{6}$ Lewis, J. S., Astrophys. J., 152, L79 (1968).

7 Lewis, J. S., Icarus, 11, 367 (1969).

${ }^{8}$ Diels, O., and Blumberg, P., Chem. Ber., 41, 82 (1908).

9 Schreiner, E., Z. Phys. Chem., 133, 420 (1928).

10 Elsey, H. M., and Lynn, G. L., J. Phys. Chem., 27, 342 (1923).

1 Garrett, A. B., and Woodruff, S. A., J. Phys. Colloid Chem., 55,477 (195i).

12 Potter, J. F., J. Atmos. Sci., 26, 511 (1969).

\section{Sea Tidally Induced Variations of the Earth's Magnetic Field (Leakage of Current from the Atlantic)}

INTEREST has recently revived in the possible effects of the sea tides on the Earth's magnetic field; modern instrumentation has made direct measurement possible ${ }^{1,2}$. Malin ${ }^{3}$ has shown how the semi-diurnal lunar variation arising from the ocean and sea tides may be inferred from the complete lunar variation observed at any given station. The time seems appropriate to begin work on detailed theoretical models taking into account the topography of the coastline. Here we continue work ${ }^{4,5}$ specifically aimed at understanding the magnitudes and distributions of ocean and sea tidally induced magnetic fields over the British Isles.

As the induced magnetic fields are very small, their effects on the motion of the sea water can be ignored. It follows that we can separately consider effects arising from oceanic tides and shallow sea tides; the results obtained can be freely added. In this communication we shall restrict our attention to the effects of tidally induced electric currents leaking from the Atlantic Ocean into the shallow seas around the British Isles as suggested by Bullard 6 . An order of magnitude estimate of the magnetic field arising is $0.15 \gamma$, except near the coast. Pending full calculations of the Atlantic Ocean electric currents caused by tides we suppose that these are unknown, but that their influence at the edge of the continental shelf is uniform. The sea is taken to be of uniform depth $(\sim 80 \mathrm{~m})$ which is much less than the ocean depth $(\sim 4 \mathrm{~km})$. The sea-ocean interface is supposed to lie along the latitudes $48^{\circ} \mathrm{N}$ and $62^{\circ} \mathrm{N}$ and the longitude $13.34^{\circ} \mathrm{W}$. These constitute the lower, upper and the left hand boundaries respectively in Figs. 1 and 2 . The land and the right hand boundary $\left(8.375^{\circ} \mathrm{E}\right)$ are taken to be insulators. The sphericity of the Earth is ignored. The dynamo 


\section{Continued from page 296}

effect of the ocean is supposed to impose a uniform electric field at the edge of the shallow seas; two cases (I and II) therefore arise: in case $I$ the inducing electric field causing leakage currents is south-north along the western boundary, and in case II it is east-west along the northern and southern boundaries. On other ocean-sea interfaces the continuity into the ocean of the tangential component of electric field is preserved; for such a large conductivity contrast this implies that the current streamlines there enter the ocean from the sea at right angles to the interface. The results obtained from cases I and II may be added vectorially by assuming a direction and amplitude for the inducing oceanic electric field. Figs. 1 and 2 illustrate the streamlines of electric currents in the seas, and the isolines of their (vertical) magnetic fields, in gammas, inland. The basic unit of length $L=111 \mathrm{~km}\left(1^{\circ}\right.$ of latitude) is used. In the numerical solution we use a graded square lattice varying in size from $L$ to $L / 16$. The Biot-Savart law is integrated exactly over each separate square of the lattice so that an accurate approximation is obtained even near the coast where the induced vertical magnetic field has a logarithmic discontinuity. The surface electric current $j$ is sealed so that $j / L$ is unity at the appropriate edge of the system, and the differences between numbers attached to streamlines (and coastlines) are proportional to the total currents flowing between them. The magnetic field is scaled differently, in order to avoid the possibility of misinterpretation. We use an estimate of $y \sim 10 \mathrm{~cm} \mathrm{~s}^{-1}$ for the ocean tidal streaming velocity, yielding an electric field $v B \sim 4.3$ e.m.u. Taking the integrated surface conductivity of the sea to be $3 \times 10^{-7}$ e.m.u. gives a surface current of $0.13 \times 10^{-5}$ e.m.u. in the sea on the boundary with the ocean. As these are rough figures ${ }^{6} v$ may be larger. On the other hand, internal short circuiting in the ocean will certainly reduce the electric field from the estimate $v B$. We have therefore rounded off the current-magnetic field scaling factor to $0.15 \times 10^{-5}$ e.m.u. All magnetic fields in Figs. 1 and 2 arise from the electric currents shown there, but they are multiplied by $0.15 \times 10^{-5} \gamma$. We also note that the induced magnetic field becomes infinite on the coast, but this is difficult to show on the diagram.

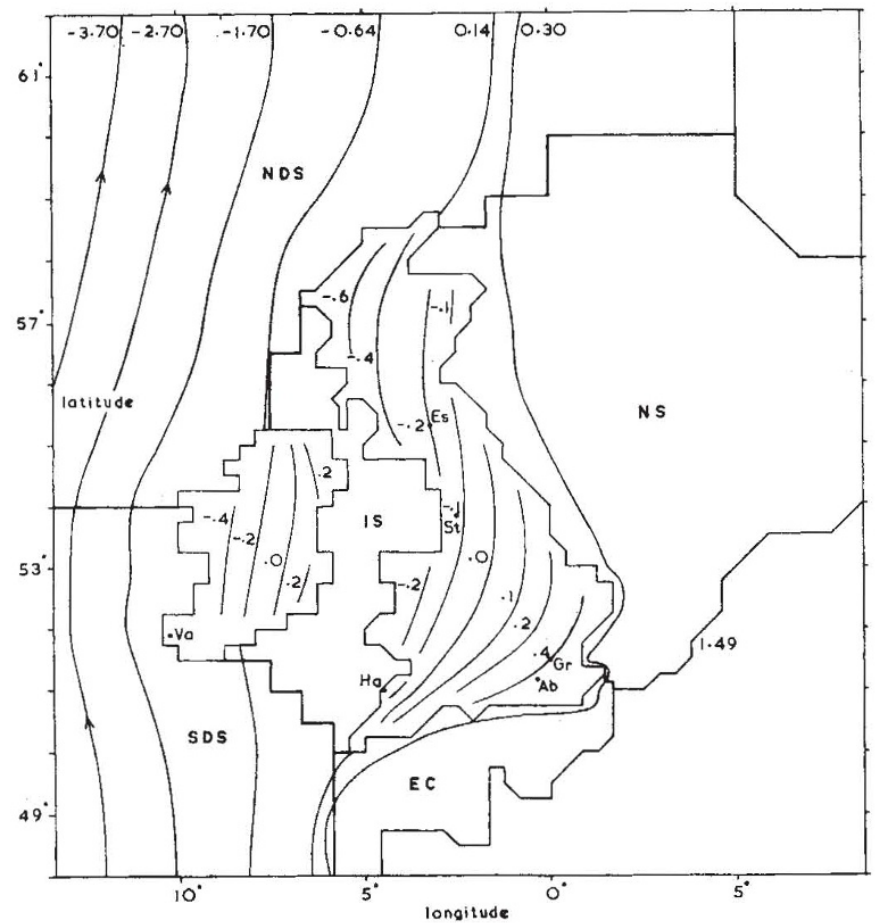

Fig. 1 Case I (see text). The electric current streamlines in the seas (for units see text) and the isolines of vertical magnetic field intensity (in gammas) inland.

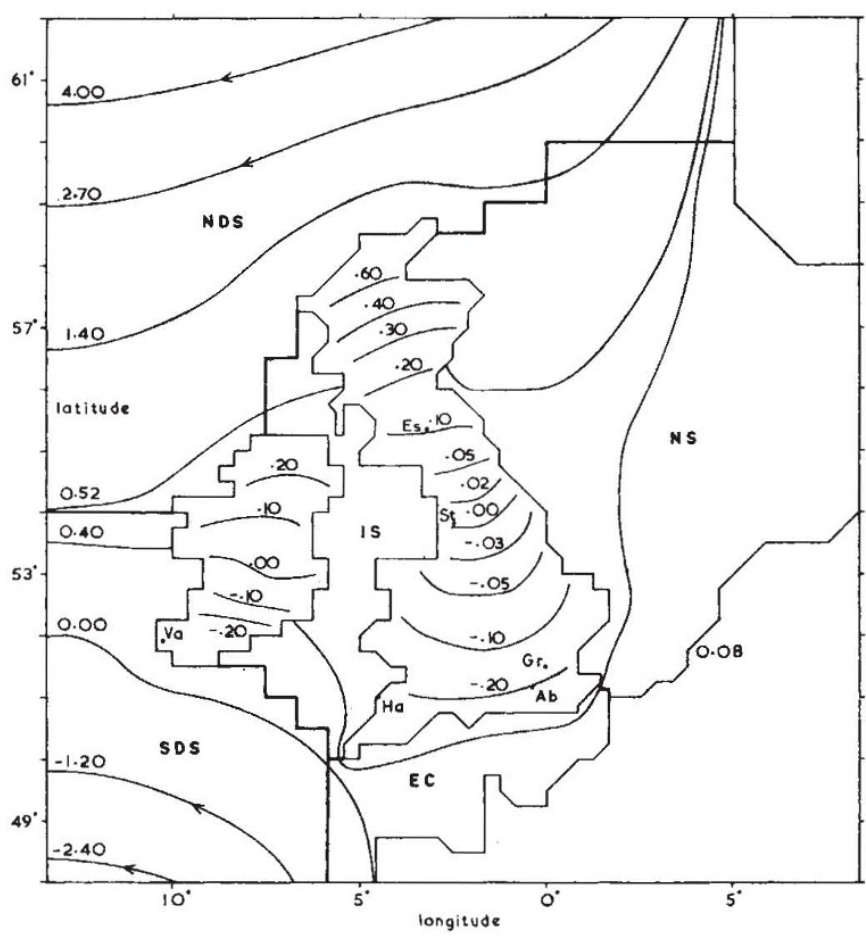

Fig. 2 Case II; otherwise as for Fig 1.

Tables 1 and 2 show in more detail the magnetic effects arising at stations within the British Isles from electric currents flowing in the various shallow seas. For this purpose we have divided the seas as shown on the maps into the Irish Sea (IS), English Channel (EC), North Sea (NS), Southern Deep Sea (SDS) and Northern Deep Sea (NDS). The results are scaled as before. We note the comparatively strong effects at coastal stations such as Hartland and Valentia, the relatively strong EC-NS effects at Abinger and Greenwich, and the IS-NS cancelling effects at Eskdalemuir in the case of south-north currents (case I). The difference between the amplitudes of the vertical lunar semidiurnal magnetic field variations observed at Greenwich and Abinger ${ }^{7}$ is $0.41 \gamma$. This is four times larger than the theoretical difference which we have calculated here from leakage of tidally induced electric currents arising in the Atlantic Ocean. It seems, then, that leakage currents cannot

Table 1 Case I: Vertical Magnetic Perturbation calculated for Various Stations within the British Isles

\begin{tabular}{lrrrrrr} 
& SDS & NDS & IS & EC & NS & Total \\
Abinger & -0.07 & -0.05 & -0.04 & 0.47 & 0.13 & 0.44 \\
Eskdalemuir & -0.05 & -0.17 & -0.13 & 0.03 & 0.12 & -0.20 \\
Greenwich & -0.06 & -0.05 & -0.04 & 0.32 & 0.20 & 0.37 \\
Hartland Pt & -0.17 & -0.06 & -0.28 & 0.21 & 0.04 & -0.26 \\
Stonyhurst & -0.06 & -0.11 & -0.12 & 0.05 & 0.12 & -0.13 \\
Valentia & -1.46 & -0.07 & 0.06 & 0.03 & 0.02 & -1.41 \\
Ab minus Gr & -0.01 & 0.00 & 0.00 & 0.15 & -0.07 & 0.07 \\
\hline
\end{tabular}

See text and diagrams for division into shallow seas.

Table 2 Case II

\begin{tabular}{lcccccr}
\hline & SDS & NDS & IS & EC & NS & Total \\
Abinger & -0.04 & 0.06 & -0.01 & -0.17 & -0.03 & -0.19 \\
Eskdalemuir & -0.04 & 0.18 & -0.01 & -0.01 & -0.01 & 0.11 \\
Greenwich & -0.03 & 0.06 & -0.01 & -0.12 & -0.05 & -0.16 \\
Hartland Pt & -0.13 & 0.07 & -0.15 & -0.11 & -0.01 & -0.33 \\
Stonyhurst & -0.04 & 0.11 & -0.02 & -0.02 & -0.02 & 0.01 \\
Valentia & -0.63 & 0.09 & 0.01 & 0.00 & 0.00 & -0.54 \\
Ab minus Gr & -0.01 & 0.00 & 0.00 & -0.05 & 0.02 & -0.03 \\
\hline
\end{tabular}

Measurements were as for Table 1. 
be completely ruled out in connexion with lunar semidiurnal variations, but they may be small. The faster streaming velocities observed in the shallow seas and the regions bordering on the continental shelf make it easier to produce somewhat larger effects more locally, and these are under investigation.

We note that if due allowance is made for inductance effects, parts of our model may approximate the situation in which electric currents are induced in the shallow seas by more rapid geomagnetic variations.

We thank Miss L. C. Thackeray and Miss C. Wright for assistance.

D. W. Windle

P. C. Kendall

H. W. GRETTON

Department of Applied Mathematics and Computing Science, University of Sheffield

Received February 22, 1971.

${ }^{1}$ Hill, M. N., and Mason, C. S., Nature, 195, 356 (1962).

${ }^{2}$ Larsen, J. C., Geophys. J. Roy. Astron. Soc., 16, 47 (1968).

${ }^{3}$ Malin, S. R. C., Planet. Space Science, 17, 487 (1969).

4 Kendall, P. C., and Chapman, S., Q. J. Mech. Appl. Math., 23, 535 (1970).

5 Chapman, S., and Kendall, P. C., Planet. Space Sci., 18, 1597 (1970).

${ }^{6}$ Pekeris, C. L., and Accad, Y., Phil. Trans. Roy. Soc., 265, 413 (1969).

${ }^{7}$ Leaton, B. R., Malin, S. R. C., and Finch, H. F., Royal Observatory Bull., No. 63 (1962).

\section{Terminal Cretaceous Events}

SEVERAL explanations have been offered (see refs. 1-3) for the abrupt faunal extinctions at the end of the Cretaceous and, with the advent of the JOIDES Deep Sea Drilling Project, it was hoped that the nature of the extinctions-at least for calcareous microfossils-would be found by coring a transitional sequence across the boundary in deep sea facies. Unfortunately, the results from the few JOIDES holes so far penetrating the Cretaceous-Tertiary boundary indicate that the unconformity is even greater in the deep ocean basins than on the continents and that a transitional sequence will probably never be found, especially in calcareous pelagic sediments. Although disappointing on first inspection, these data never- theless provide the most tangible and significant clue yet as to the nature of the terminal Cretaceous event.

The late Maastrichtian was a time of general worldwide decrease of temperature with climatic belts becoming more sharply differentiated ${ }^{4-9}$. It was also a time of greatly reduced clastic influx into the oceans resulting from almost worldwide orogenic quiescence ${ }^{1,2,10}$. The only major orogeny was the Laramide Revolution in the western interior of North America, the sediments of which apparently never reached marine environments except in the restricted interior sea in which the Lance Group was deposited. It therefore seems likely that the Laramide Revolution, the sediments of which hold the key to terrestrial-marine correlations at the time of the Cretaceous-Tertiary event, was not a significant contributor of carbonate and nutrients to the world's oceans, to which the supply of nutrients and carbonate was then severely restricted $^{2,10}$.

These sediments do, however, preserve a remarkably complete record of megaphyta and dinosaurs that adds considerably to knowledge of the effects of the Cretaceous-Tertiary event on land. Although the megaphyta are thought to have been little affected by the event, Hall and Norton ${ }^{6}$ described a palynologically significant change across the boundary in the North-Central United States (Larimide sediments) showing rapid replacement of thermophilic dicotyledons by temperate gymnosperms just above the highest dinosaur remains. There is no apparent sedimentary break at the locality. The area is especially significant because the lignite in which the Cretaceous-Tertiary boundary is preserved is laterally equivalent to the lignite just below the base of the fossiliferous marine Cannonball Formation of North Dakota, where there is a nearly continuous Cretaceous-Tertiary sequence ${ }^{8,11}$. Although calcareous nannofossils are virtually absent in the Cannonball, attesting to its restricted marine environment, rare planktonic foraminifera document its lowest Danian age ${ }^{12}$.

In open marine environments, calcareous shelf sections in which rocks of latest Maastrichtian age are known everywhere present similar lithologies. The strata are always rich in glauconite and contain significant amounts of phosphate, both indications of slow deposition ${ }^{2}$. Most of these Upper Maastrichtian marl or chalk beds contain little detritus and many are rich in planktonic foraminifera and nannofossils, an indication that the water column above them was neither hypersaline nor brackish. There are usually hardgrounds or
Fig. 1 Age relationships and present configuration of sediments draped across the mid-Atlantic Ridge at about latitude $30^{\circ} \mathrm{S}$, showing the magnitude of the Cretaceous Tertiary Unconformity.

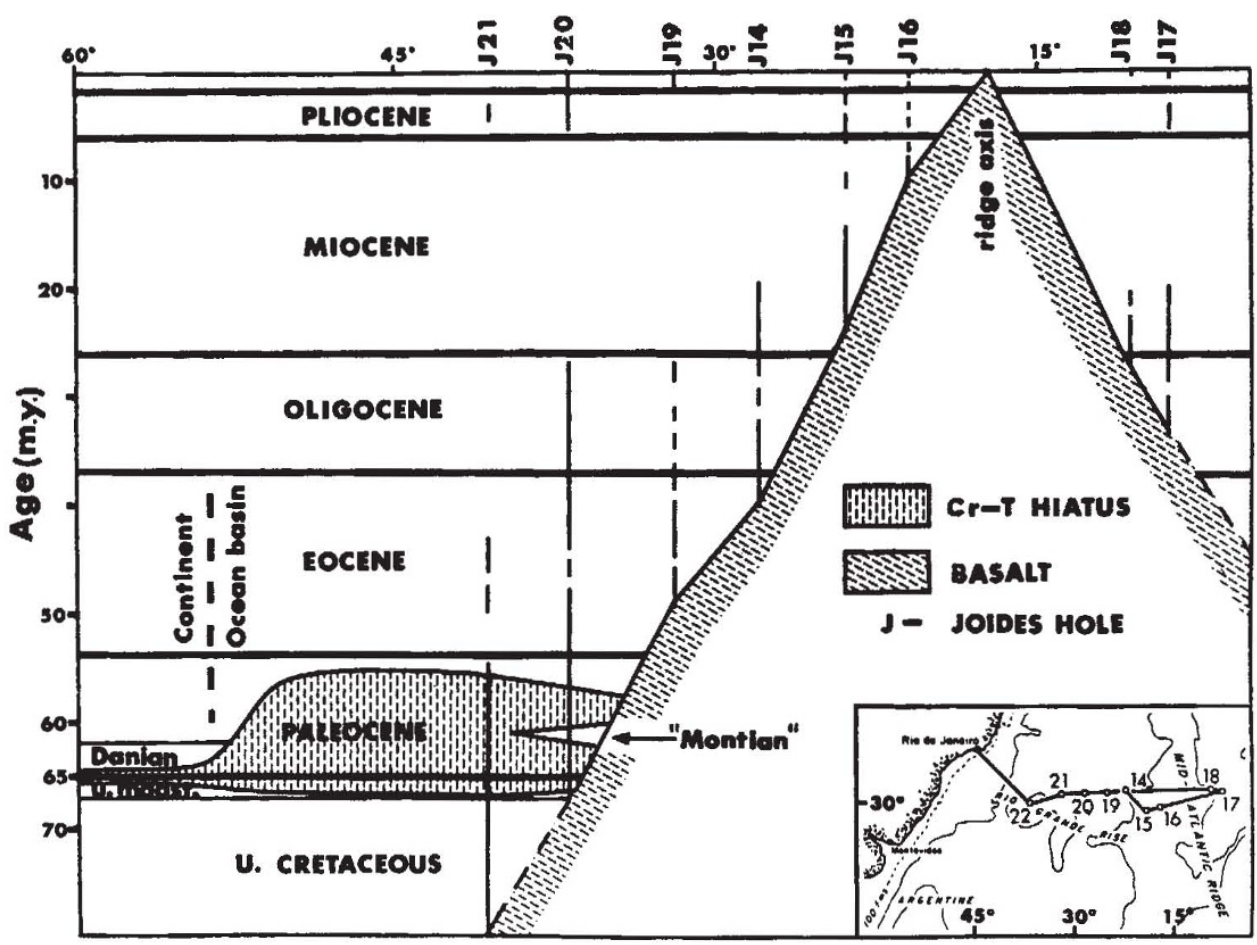

C 1971 Nature Publishing Group 